\title{
PERANCANGAN MEDIA PEMBELAJARAN E-TEMBANG BERBASIS ANDROID UNTUK BERBAGI ILMU TEMBANG MACAPAT
}

\author{
Dani Sasmoko', Haryo Kusumo² \\ ${ }^{1}$ Manajemen Informatika, ,2Akutansi Komputer Sekolah Tinggi Elektronika dan Komputer Semarang \\ 1dani@stekom.ac.id, ${ }^{2}$ haryo@stekom.ac.id
}

\begin{abstract}
Along with the development of information technology, especially in the field of communication, the use of Android mobile phones has become commonplace. The tedious and monotonous learning process of Tembang Mocopat generates the students' disinterest in learning it at school. Regarding this, E-Tembang is used to increase students'interest at school and help to preserve the culture of Tembang macapat . This study used the $R \& D$ method to conduct the research and Android Studio to create the application and took 100 respondents for their opinions. The result of this study indicated that $78 \%$ show interest in using E-Tembang, while $66 \%$ like and are interested and $86 \%$ want to use it. However, it is undeniable that $23 \%$ of students do not like learning by using mobile telephones and prefer to study in the classroom. Basically, students will like to learn any subject that is attractive to them. By using E-Tembang students can learn together at home and share the knowledge of tembang macapat.
\end{abstract}

Keywords: earning media, android, macapat, elementary school

\section{Pendahuluan}

Dewasa ini perkembangan teknologi sangat pesat terutama di bidang pemprograman mobile di mana perangkat telepon genggam sekarang sudah sangat merakyat. Hampir tiap individu memiliki telepon genggam terutama yang berbasis android. Anak-anak sangat sering menggunakan perangkat ini untuk mengakses game dan media sosial. Ketertarikan anak terhadap penggunaan perangkat telepon genggam karena di sana mudah membawa nya, menggunakan suara dan gambar yang menarik. Ini berbanding terbalik dengan ketertarikan anakanak ternahadap budaya Indonesia dalam hal ini tembang macapat, anak-anak sangat tidak tertarik karena media pengenalan nya terhadap budaya tembang ini masih berupa di lantunkan dan media buku sebagai sarana informasi(Natalia and Khotimah 2016).

Menurut Kepala Sekolah SD Purwoyoso 4 Semarang anak-anak sangat sulit mendapat sumber pengetahuan tembang macapat karena keterbatasan guru atas tembang itu sendiri dan media yang di bawa kan tidak menarik di mata anak-anak. Penggunaan media buku sebagai sarana informasi tembang kurang di apresiasi anak-anak karena tidak ada contoh suara lagu yang benar dan kemampuan guru untuk melagukan tembang macapat sangat terbatas hal ini menimbul kan sifat bosan pada diri anak-anak (Walansari 2011).

Penulis melakukan penelitian untuk melestarikan budaya tembang Macapat dengan memindah objek media pembelajaran nya berbasis Android sehingga di harapkan anak SD akan tertarik dan budaya tembang Macapat akan terus lestari. Proses pembelajaran anak SD berbeda dengan anak SMP atau di atas nya karena pada anak SD proses pembelajaran harus di dasari dengan sifat riang dan gembira dan tanpa tekanan apapun. Sehingga diharapkan dengan ada nya penelitian ini budaya Macapat dapat menarik minat mereka dan tembang macapat dapat terus ada. Inovasi yang di lakukan dengan melakukan bahan ajar dari yang awal nya berupa buku ke bentuk bahan ajar menggunakan aplikasi berbasis android dengan menggunakan handphone atau tablet. Materi ajar pun akan di isi dengan bahan yang menarik dan atraktif sehingga ada peran serta aktif antara peserta didik dengan bahan ajar(Mintasih 2007). Penelitian ini akan menggunakan sampel anak kelas 4-6 SD Purwoyoso 04 sebagai pengguna dan Guru pengajar Bahasa Jawa sebagai validator.

\section{Tinjauan Pustaka}

\subsection{Tembang Macapat}

Macapat adalah semacam puisi tetapi memiliki tingkat kerumitan yang sangat tinggi, sarat dengan akidah, petuah, nasihat, dan kearifan pandangan hidup masyarakat jawa, wacana yang dikenal dan membudaya dalam diri masyarakat jawa(Setiyadi 2010). Tembang Macapat merupakan salah satu bagian dari budaya tata bahasa jawa. Tata bahasa jawa sendiri meliputi antara lain aksara jawa, tembung, ater-ater seselan panambangan, homonim, antonim, sinonim, ukara, purwakarthi, tembang, 
gending, karawitan, babad wayang dan serat(Setiyorini 2016) . Pada jaman populer nya tembang Macapat ini di gunakan untuk penyampaian pesan pendidikan dan kehidupan karena sifat nya yang enak di dengar dan sesuai kondisi masyarakat dan tidak lekang oleh waktu. Sifat tembang yang gampang di hapal dan menggunakan bahasa yang mudah di mengerti sehingga masyarakat pada saat itu sering melantunkan nya (Arifudin 2017).

\subsection{Android}

Android adalah suatu platform yang sangat banyak di gunakan di berbagai merk telepon genggam. Android sendiri sebenar nya menggunakan platform linuk yang bersifat open source sehingga di mungkin kan semua orang membuat aplikasi pendukug dari Operation System ini. Android saat ini sudah terintergrasi ke berbagai perangkat sehingga telepon genggam bisa terhubung ke banyak perangkat pendukung dan memudah kan pengguna(Agus and Putra 2015).

\subsection{Bahan Ajar}

Bahan Ajar adalah segala bentuk alat bantu dan bahan yang di gunakan guru/dosen dan instruktur untuk melaksanakan kegiatan belajar mengajar. Selain itu bahan ajar merupakan alat bantu untuk siswa agar lebih mudah dan terbantu memahami materi yang di berikan pengajar yang di sesuaikan dengan karateristik materi ajar dan alat untuk mengevaluasi hasil proses pembelajaran(Bahar 2019). Pada proses belajar di perlukan peran aktif dari peserta didik dalam membangun pemahaman dan makna atas informasi yang di berikan, berdasarkan hal ini maka wujud dari bahan ajar menjadi sangat penting dalam proses belajar mengajar (Anggraeni and Kustijono 2013).

\subsection{Media Pembelajaran}

Media Pembelajaran adalah sarana penyampaian bahan ajar yang di berikan instruktur atau guru/dosen untuk menyampaikan informasi. Media Pembelajaran mengalami perubahan yang sangat segnifikan seiring perkembangan teknologi, mulai dari teknologi cetak, suara, video dan komputer ataupun gabungan dari semua itu(Saputro and Saputra 2015).

\section{Metode Penelitian}

Proses penelitian ini dilakukan dengan menggunaka metode Research and Development $(\mathrm{R}$ n D ) Borg and Gall yang mempunya beberapa tahapan antara lain (Dewi S., Zahraini, and Sabarini 2013) :

1. Penelitian dan Pengumpulan Data (Research and collecting ) pada proses ini di lakukan analisa kebutuhan dengan cara mendatangin objek penelitian dan melakukan wawancara langsung terhadap guru dan murid untuk menggali permasalahan yang terjadi di lokasi. Selain meninjau lokasi penelitian juga menggunakan studi literatur untuk mencari dari empiri dan kajian yang relevan dengan pokok penelitian yang di lakukan. Setelah itu dilakukan survei kecil untuk memastikan pokok permasalahan yang di hadapi sehungga proses pengembangan produk menghasilkan produk yang mampu memecahkan masalah di hadapi. Penelitian ini di lakukan di SD Purwoyoso 4 Semarang.

2. Perencanaan Penelitian ( Planning), Pada tahap ini melakukan perencanaan kebutuhan apa saja yang di perlukan selama tahap penelitian, merumuskan kualifikasi penelitian dan langkah-langkah apa saja yang akan di lakukan selama penelitian.

3. Pengembangan Disain (Develop Preminary of Product ) Pada langkah ini di lakukan pembuatan perancangan produk yang akan di kembangkan dengan menggunakan UML dan Flow Cart sehingga proses yang akan di buat dapat di rencanakan secara optimal. Selain itu tahap pengujian yang akan di lakukan akan di rencanakan pada tahap ini.

4. Uji Coba Awal di lapangan (Peminary Field Testing ) Pada proses uji coba ini yang akan di test adalah perancangan dan disain oleh pakar di bidang nya, apakah racangan dan interface yang di kembangkan sesuai dengan kebutuhan atau tidak.

5. Uji Coba Lapangan ( Main Field Testing ) setelah uji coba awal produk di buat dan di uji coba kan ke lokasi dengan metode wawancara membandingkan antara produk penelitian dan system yang sudah bejalan dengan objek penelitian guru dan murid untuk mengetahui apakah produk yang di kembangkan mampu mengurai permasalahan yang terjadi.

6. Revisi dan Implementasi

Pada tahap ini dilakukan revisi dari uji coba di lapangan apabila terdapat kekurangan dan di implementasikan ketika sudah mampu menanggulangi permasalahan yang terjadi

\section{Pembahasan dan Analisa}

\section{Alur dari aplikasi :}




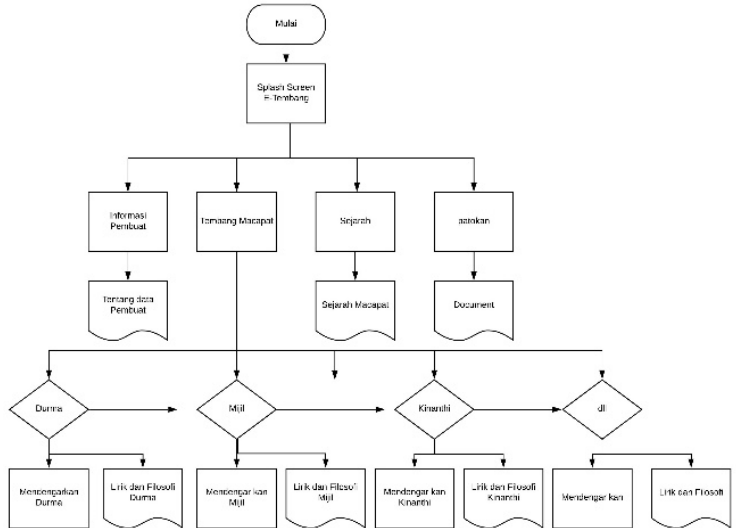

Gambar 1. Alur Aplikasi E-tembang

Pada gambar 1 dijelaskan ketika aplikasi di buka akan tampil pertama adalah logo splash screen Etembang yang kemudian akan di arah kan ke menu.

Di dalam Menu terdapat 4 tombol yaitu antara lain tombol informasi, Tembang Macapat, Sejarah dan Patokan. Kemudian di dalam informasi berisi tentang logo institusi pembuat, nama pembuat, alamat yang dapat di hubungi dari pembuat. Pada Tombol Tembang Macapat ketika di tekan akan di arahkan ke dalam halaman yang berisi 11 lagu dari tembang macapat, dan ketika salah satu nya di tekan akan mengarah kan ke dalam halaman isi dari tembang tersebut. Pada Tombol Sejarah ketika di tekan akan di arah kan ke halaman sejarah tentang tembang macapat itu sendiri, sedangkan pada pathokan berisi patokan tinggi nada dalam melaguka tembang macapat.

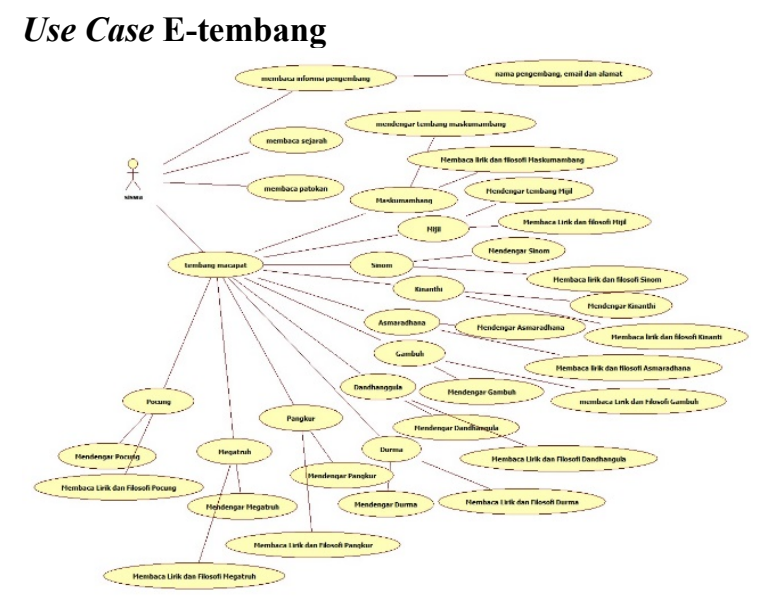

Gambar 2 Use Case E-tembang

Pada gambar 2 ini terlihat hanya terdapat 1 pengguna hal ini di karenakan aplikasi yang di buat tidak menggunakan server dan hanya off line hal ini di karenakan agar siswa yang menggunakan aplikasi ini akan lebih hemat bandwith internet karena ketika menggukan aplikasi ini tidak memakai internet, karena pada proses belajar tembang mendengar kan lagu macapat akan di lakukan berulang-ulang sehingga jika menggukan internet akan mengakibatkan membengkak nya penggunaan kouta internet.

Proses belajar tembang bisa di lakukan dengan menekan tombol Tembang Macapat dan kemudian memilih tembang apa yang akan di pelajari dan kemudian di lanjut dengan halaman tembang itu sendiri yang berisi lirik, filosofi dan tombol untuk menyalakan dan menghentikan lagu tembang macapat yang di pilih.

\section{Tampilan Aplikasi}

\section{Splash Screen}

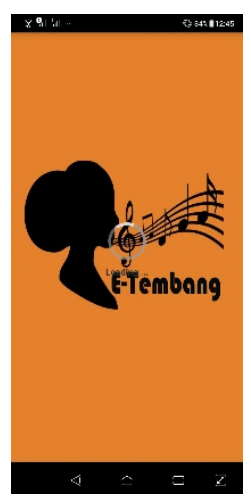

Gambar 3. Splash Screen E-tembang

Pada gambar 3 terdapat Splas Screen, ini adalah tampilan yang akan muncul ketika icon Etembang di tekan, fungsi dari spash screen Etembang adalah suatu kondisi dimana terdapat image yang menggambar kan aplikasi dan pada kondisi sedang loading .

\section{Menu}

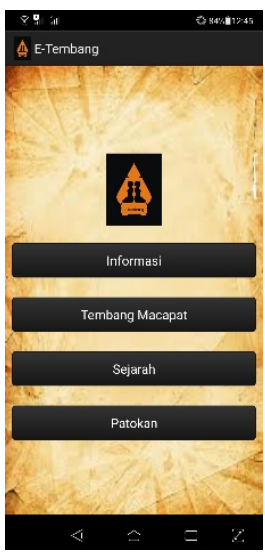

Gambar 4. Menu E-tembang

Kita dapat menemui Menu E-tembang pada gambar 4. Ini adalah tampilan setelah splash screen di mana di menu ini terdapat 4 buah tombol yaitu informasi, Tembang Macapat, Sejarah dan Patokan.

\section{Informasi}




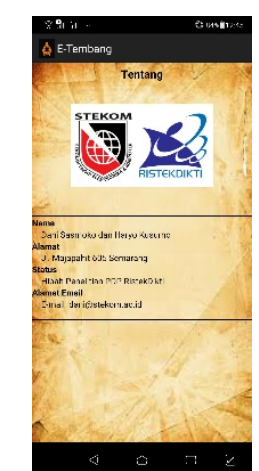

Gambar 5. Isi dari Iformasi

Pada gambar 5 berupa informasi berisi tentang data pembuat yang tertera adalah institusi, nama, alamat dan email dari pembuat aplikasi.

\section{Tembang Macapat}

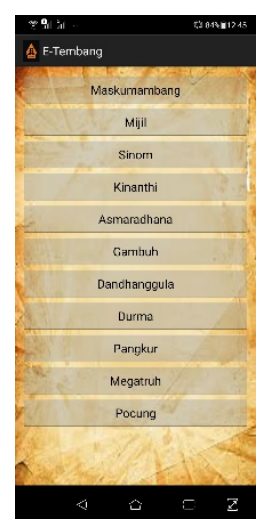

Gambar 6. Menu Tembang Macapat

Gambar 6 menjelaskan tentang Menu Tembang. Ini berisikan 11 lagu tembang macapat antara lain : Maskumambang, Mijil, Sinom, Kinanthi, Asmaradhana, Gambuh, Dandhanggula, Durma, Pangkur, Megatruh, Pocung.

Ketika salah satu dari 11 tembang ini kita pilih makan selanjut nya akan di arah kan ke halaman isi dari tembang tersebut.

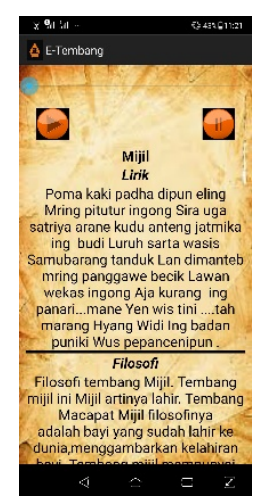

Gambar 7. Isi dari Tembang Macapat

Pada gambar 7 adalah tampilan pada tembang Mijil. Ketika tombol mijil di pilih, selanjutkan akan di arah kan ke halaman tembang Mijil yang berisi pemutar lagu tembang mijil, lirik tembang mijil dan filosofi yang terkandung di dalam tembang tersebut.

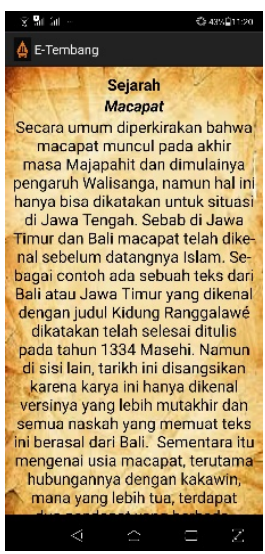

Gambar 8. Halaman Sejarah Macapat

Gambar 8 adalah halaman Sejarah. Pada halaman ini berisi tentang sejarah singkat tembang macapat ini muncul pertama kali dan pengaruh apa yang melandasi terbentuk nya tembang ini .

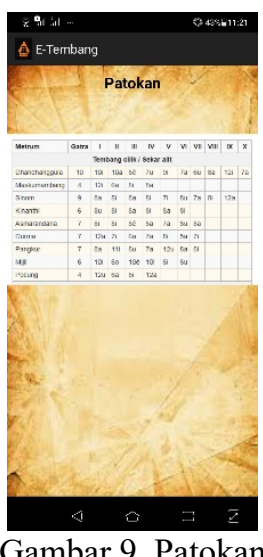

Gambar 9 berisi tentang aturan tembang atau biasa di sebut Patokan. Patokan ini merupakan landasan dalam menembang atau melagukan tembang macapat dan merupakan aturan dasar untuk melagukan tembang macapat.

Pada aplikasi ini di kenalkan pada anak-anak sekolah dasar dengan sasaran pada SD di Semarang dengan jumlah responden 100 orang. Pada pelaksanaan nya anak-anak di kenal kan aplikasi ini dan kemudian di minta pendapat nya tentang aplikasi ini dan pembandingan dengan pembelajaran yang sudah pernah di lakukan tentang tembang macapat. Dari hasil wawancara dan Survie tersebut di peroleh hasil sebagai berikut

\section{Analisa}




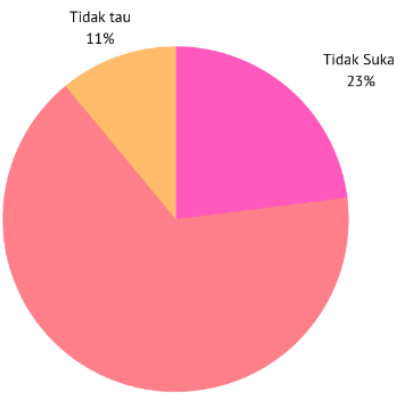

Suka

Gambar 10. Gambar grafik tingkat penerimaan aplikasi E-tembang

Gambar 10 menjelaskan tingkat siswa mau menerima. Pada grafik ini dapat di ketahui ada $66 \%$ anak menyukai aplikasi tersebut dengan banyak alasan antaralain mudah, tidak perlu membawa buku, tidak membosan kan. Sedangkan 23\% mengakui tidak menyukai belajar menggunakan telepon genggam di karenakan malas belajar di rumah, lebih menyukai belajar di dampingin guru, dan telephone genggam nya terlalu kecil sehingga tulisan menjadi sangat kecil. Sisan nya sebesar $11 \%$ bingung dan tidak tau akan menjawab apa.

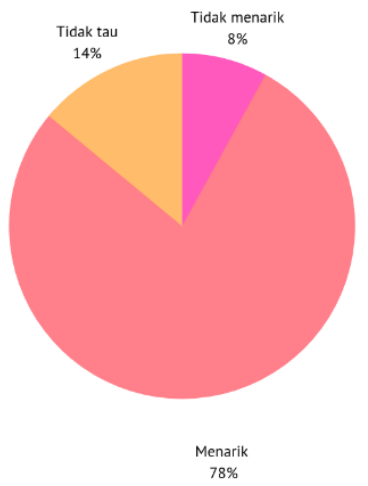

Gambar 11. Gambar grafik menarik tidak aplikasi Etembang.

Pada gambar 11 dapat di lihat tingkat ketertarikan responden atas disan dan isi dari aplikasi E-tembang sebanyak $78 \%$, anak-anak tertarik karena untuk mencari contoh tembang dan lirik tembang yang benar mudah di dapat serta di mengerti, selain itu suara tembang yang menarik dan bagus menjadi salah satu alasan menarik dari aplikasi ini. Sedangkan sebanyak 8\% mengatakan tidak menarik karena lebih menyukai guru yang menembang secara langsung dan bisa bertanya ketika kesulitan dan bisa mengerti benar salah nya. 14\% mengatakan tidak tau dan kebingungan dalam menjawab nya.

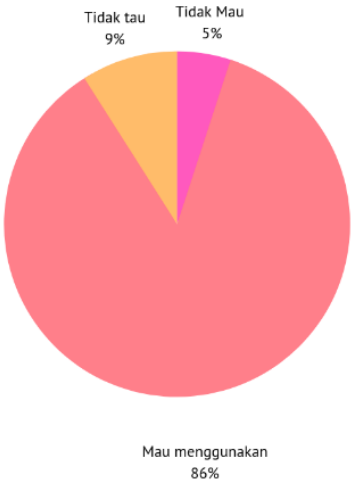

Gambar 12. Gambar grafik tingkat mau menggunakan aplikasi E-tembang

Pada grambar12 terdapat $86 \%$ mau menggunakan aplikasi E-tembang dalam proses belajar tembang macapat karena di rasa lebih mudah dan menarik serta tidak membosan kan karena bisa di bawa ke mana saja dan bisa di gunakan untuk melajar kelompok. Sedangkan sebanyak 5\% mengatakan tidak mau karena lebih menyukai belajar di kelas serta lebih nyaman belajar ketika ada guru nya. Sisa nya sebanyak $9 \%$ mengatakan tidak tau apakah ingin menggunakan atau tidak.

\section{Kesimpulan}

Pada proses belajar ternyata faktor menarik dan tidak nya suatu materi sangat menentukan keinginan seorang siswa mau belajar. Proses pembelajaran dengan media digital ternyata tidak langsung semerta-merta menarik minat siswa belajar hal ini bisa di buktikan dari gambar.10 di mana ada 23\% siswa tidak menyukai belajar dengan media digital dan masih mengingin kan belajar model konvesional yang ada di dalam kelas dan di dampingin guru. Akan tetapi pada gambar.11 sebanyak 78\% mengatakan aplikasi ini menarik karena mudah menggukan dan isi dari lagu tembang menggunakan sumber dengan suara yang enak di dengar kan. Pada gambar.12 sebanyak 86\% mau menggunakan aplikasi ini untuk proses belajar tembang macapat karena akan mempermudah kan siswa belajar dan dapat di gunakan di mana saja, tidak harus di dalam kelas saja.

Jadi pada kenyataan nya penelitian ini dapat di terima oleh responden dan akan di gunakan untuk proses belajar tembang macapat di karenakan mudah hanya perlu di install di telepon genggam. Siswa tidak di repotkan dengan penggunaan buku, suara pengisi tembang di aplikasi yang menarik ternyata menjadi salah satu daya tarik siswa di bandingkan ketika belajar di kelas yang menggunakan suara guru atau media lain nya.

Aplikasi E-tembang dapat di terima oleh siswa dengan sebagian besar mau menggunaka hal ini 
berarti siswa tertarik akan hal baru dan aplikasi ini dapat di gunakan di mana saja dan tidak tergantung oleh kelas dan waktu belajar di sekolah sehingga siswa dapat belajar di rumah atau pun membentuk kelompok belajar di luar sekolah.

\section{Daftar Pustaka:}

Agus, I Gede, and Maha Putra. 2015. “APLIKASI PEMBELAJARAN NYANYIAN PUPUH TADISIONAL BALI BERBASIS ANDROID DI SEKOLAH DASAR LEARNING APPLICATION OF THE BALINESE TRADITIONAL PUPUH SONGS WITH ANDROID PLATFORM IN ELEMENTARY SCHOOL." In E-Proceeding Of Applied Science, , 1051-58.

Anggraeni, Retno Dian, and Rudy Kustijono. 2013. "Pengembangan Media Animasi Fisika Pada Materi Cahaya Dengan Aplikasi Flash Berbasis Android." Jurnal Pendidikan Fisika dan Aplikasinya (JPFA) 3(1): 11-18.

Arifudin, Hendrik Rusdian. 2017. "Perancangan Aplikasi Pembelajaran Seni Budaya Tembang Macapat Berbasis Android." Journal of Computer and Information Technology 1(1): 39-45.

Bahar, Bahar. 2019. "PENGAYAAN BAHAN AJAR SEKOLAH DASAR PASCA PEMBELAJARAN DI KELAS SMART LKS: MODEL APLIKASI PEMBELAJARAN BERBASIS TEKNOLOGI MOBILE UNTUK PENGAYAAN BAHAN AJAR SEKOLAH DASAR PASCA PEMBELAJARAN DI KELAS." Jurnal teknologi Informasi dan Komunikasi 10: 1-6.

Dewi S., Anita Chandra, Dian Ayu Zahraini, and Sri Sabarini. 2013. "Desain Pengembangan Anak Usia Dini Holistik Integratif PAUD Non Formal (Penelitian Research and Development Di Pos PAUD Mutiara Kelurahan Lamper Lor Kecamatan Semarang Selatan)." Jurnal Penelitian PAUDIA 2(1): 105-26.

Mintasih, Diyah. 2007. "Pengembangan Bahan Ajar Berorientasi Kkni Untuk Penguatan Scientific Approach Pada Mata Kuliah Evaluasi Dan Proses Pembelajaran Matematika." Journal AL-Manar 6(1): $1245-49$.

Natalia, Lusi, and Khusnul Khotimah. 2016. "Pengembangan Media Computer Assisted Instruction Pada Mata Pelajaran Bahasa Daerah Materi Aksara Jawa Untuk Siswa Kelas VII Di SMP Kartika IV-11 Surabaya PENGEMBANGAN MEDIA COMPUTER ASSISTED INSTRUCTION PADA MATA PELAJARAN BAHASA DAERAH
MATERI AKSARA JAWA." Jurnal Mahasiswa Teknologi Pendidikan 7(2): 1-6.

Saputro, Rujianto Eko, and Dhanar Intan Surya Saputra. 2015. "Pengembangan Media Pembelajaran Mengenal Organ Pencernaan Manusia Menggunakan Teknologi Augmented Reality." Jurnal Buana Informatika 6(2): 153-62. https://ojs.uajy.ac.id/index.php/jbi/article/view/404.

Setiyadi, Dwi Bambang Putut. 2010. "Wacana Tembang Macapat Sebagai Pengungkap Sistem Kognisi Dan Kearifan Lokal Etnik Jawa." Kajian Linguistik dan Sastra 22 No.2(1): 193-210.

Setiyorini, Agustin. 2016. "Aplikasi Tembang Macapat Berbasis Multimedia." Jurnal Informasi Interaktif 1(2): 87-92.

Walansari, Ike Desi. 2011. "PENGGUNAAN MEDIA NAOKE ( NEMBANG KARAOKE ) DALAM PEMBELAJARAN TEMBANG DOLANAN KELAS IV SDN SUMUR WELUT 1 / 438 SURABAYA." JPGSD 6(4). 